\title{
High Serum Ferritin in Adult-Onset Still's Disease
}

\author{
Peter Jandus ${ }^{1}$, Wei Wang ${ }^{2}$, Michael Seitz ${ }^{1}$, Felix Wermelinger ${ }^{1}$, Arthur Helbling ${ }^{3}$, Hans-Peter Kohler ${ }^{2}$ \\ ${ }^{1}$ Department of Rheumatology and Clinical Immunology/Allergology, University Hospital, Bern, Switzerland; ${ }^{2}$ Department of Inter- \\ nal Medicine, Spital Netz Bern Ziegler, Bern, Switzerland; ${ }^{3}$ Allergy Unit, Department of Internal Medicine, Spital Netz Bern Ziegler, \\ Bern, Switzerland. \\ Email: peter.jandus@insel.ch
}

Received August 19 ${ }^{\text {th }}, 2010$; revised August 21 ${ }^{\text {st }}, 2010$; accepted Novermber $3^{\text {rd }}, 2010$.

\begin{abstract}
In August 2009, a 28-year-old Spanish woman was referred in reduced general condition after at least four medical consultations with a 2 week history of remittent fever, night sweats, exanthema and intermittent arthralgias. Noticeable in the clinical examination was only an urticarial rash on the trunk and extremities and body temperature of $39.6^{\circ} \mathrm{C}$. Laboratory tests: WBC with a slight left shift (32\%), mild thrombocytopenia $(128 \mathrm{G} / \mathrm{l}), \mathrm{CRP} 78 \mathrm{mg} / \mathrm{l}(\mathrm{N}:<5)$, elevated transaminases [ASAT $67 \mathrm{U} / \mathrm{l}$ (N: 10-37), ALAT $45 \mathrm{U} / \mathrm{l}$ (N: 30-65)]. On the fifth day maximum values for ASAT $322 \mathrm{U} / \mathrm{l}$ and ALAT $378 \mathrm{U} / \mathrm{l}$ were reached. During hospitalisation recurrent fever up to $39.0^{\circ} \mathrm{C}$ has been documented associated with arthralgias and myalgias. An infection with blood cultures and serology tests was excluded. Rheumatology analysis, urine analysis, chest X-ray, and abdominal ultrasound were inconspicuous. A serum ferritin level of $5493 \mu \mathrm{g} / \mathrm{l}(\mathrm{N}$ : 23110) was detected with peak four days later $(8530 \mu \mathrm{g} / \mathrm{l})$. AOSD was suspected and prednisolone $(1 \mathrm{mg} / \mathrm{kg}$ body weight $)$ started. The patients recovered rapidly. Transaminases (ASAT $47 \mathrm{U} / \mathrm{l}$, ALAT $149 \mathrm{U} / \mathrm{l}), \mathrm{CRP}$ (34 mg/l), and ferritin level $(1969 \mu \mathrm{g} / \mathrm{l})$ regressed within 3 days. 3 months later, prednisolone was discontinued; she presented fever $\left(40^{\circ} \mathrm{C}\right)$, myalgias, macular rash on the trunk, sore throat and oligoarthritis. Laboratory tests including WBC were without pathologic findings except for transaminases (ASAT $83 \mathrm{U} / \mathrm{l}$, ALAT $53 \mathrm{U} / \mathrm{l}), \mathrm{CRP}(370 \mathrm{mg} / \mathrm{l})$ and ferritin $(7434 \mu \mathrm{g} / \mathrm{l})$. An infectious process was excluded. After resumption of prednisolone $10 \mathrm{mg}$ daily, quick relief of symptoms occurred. Given the short time of relapse, immunosuppressive therapy with cyclosporin was initiated (4 $\mathrm{mg} / \mathrm{kg}$ body weight). Since that time the patient remained symptom free for over 8 months.
\end{abstract}

Keywords: High Ferritin, AOSD, Fever, Arthralgia, Rash

\section{Introduction}

Adult onset Still's disease (AOSD) is a rare systemic inflammatory disease of unknown etiology that is characterized by spiking high-fever usually exceeding $39^{\circ} \mathrm{C}$, skin rash, and arthralgia [1]. Clinical manifestations of AOSD are multi-faceted and mimic various other diseases such as infections, neoplasm or autoimmune diseases [2]. Patients need often many medical consultations since suspicion arises at a later date. Especially in times of pandemic flu, a correct diagnosis is difficult to establish and might be more delayed than usual. Recently, serum ferritin has been shown as a useful diagnostic and disease activity monitoring marker in AOSD [2].

\section{Case}

In August 2009, a 28-year-old Spanish woman was referred because of remittent fever, exanthema and intermittent arthralgias. Two weeks ago she complained about inspiratory chest pain, polyarthralgias (hands and feet), sore throat, and temperature of $37.6^{\circ} \mathrm{C}$. One week later she presented an itchy erythema on arms and legs to the primary care physician. Despite treatment with ibuprofen $400 \mathrm{mg}$ three times daily and cetrizin $10 \mathrm{mg}$ twice daily, she showed up 24 hours later at the emergency room of a hospital because of severe knee pain and fever of $38.2^{\circ} \mathrm{C}$. Except for hives on arms and legs, the clinical examination was completely normal without any signs e.g. for joint effusions. The dermatologist consultant prescribed prednisolone (Pdn) $25 \mathrm{mg}$ daily, levocetirizin $5 \mathrm{mg}$ four times daily and a topical therapy with clobetasolpropionat. Over the next days the patient noticed recurrent fever up to $40^{\circ} \mathrm{C}$, night sweats, myalgias, sore throat, and worsening of the itchy erythema. Finally, she went to an outpatient clinic and was referred in a reduced general condition to our hospital. 
Medical history was bland (alcohol abstinent, no illicit drug abuse, never-smoker). Noticeable in the clinical examination was only an urticarial rash on the trunk and extremities, body temperature $39.6^{\circ} \mathrm{C}$. Laboratory tests: WBC with a slight left shift $(32 \%)$, mild thrombocytopenia $(128 \mathrm{G} / \mathrm{l})$, CRP $78 \mathrm{mg} / \mathrm{l}(\mathrm{N}:<5)$, elevated transaminases [ASAT $67 \mathrm{U} / 1$ (N: 10-37), ALAT 45 U/1 (N: 3065)]. On the fifth day maximum values for ASAT 322 U/1 and ALAT $378 \mathrm{U} / 1$ were reached. Differential diagnosis focused primary on infection of unknown origin and non-specific inflammatory process. During hospitalisation recurrent fever up to $39.0^{\circ} \mathrm{C}$ has been documented associated with severe arthralgias and myalgias. All blood cultures as well as serology tests for EBV, parvovirus B19; hepatitis A, B, C, HIV, TPHA and ASLO were negative. Anti-liver antibody, rheumatoid factor, urine analysis, chest X-ray, and abdominal ultrasound were all normal. Protein serum-electrophoresis showed a slight dysproteinaemia (elevated $\alpha 1$ [7.6\%], $\alpha 2$ [13.4\%]), and ANA was elevated at 1:640 with speckled pattern. Remarkably, a striking increased serum ferritin level of $5493 \mu \mathrm{g} / \mathrm{l}$ (N: 23-110) was detected with peak four days later with $8530 \mu \mathrm{g} / \mathrm{l}$. AOSD was suspected and treatment with Pdn started with an initial dose of $1 \mathrm{mg} / \mathrm{kg}$ body weight. The patient recovered rapidly, felt symptom free. The transaminases (ASAT 47 U/1, ALAT 149 U/1), CRP (34 mg/l), and ferritin level (1969 $\mu \mathrm{g} / \mathrm{l})$ regressed within 3 days. 3 months later, and Pdn was discontinued the patient presented 2 weeks after beginning of her symptoms at the University Clinic for Rheumatology again in a reduced general condition with fever of $40^{\circ} \mathrm{C}$, myalgias, macular rash on the trunk, sore throat and oligoarthritis. Despite an antibiotic therapy (positive rapid streptococcal a test in the throat swab) one week prior to the admission symptoms persisted. Laboratory tests incl. WBC were without pathologic findings except for slightly elevated transaminases (ASAT $83 \mathrm{U} / 1$, ALAT $53 \mathrm{U} / 1$ ), high CRP $370 \mathrm{mg} / \mathrm{l}$ ) and a high ferritin value of $7434 \mu \mathrm{g} / \mathrm{l}$. An infectious process was repeatedly excluded. In the CT scan of chest and abdomen only a splenomegaly of $13 \mathrm{~cm}$ was noteworthy. After resumption of the treatment with pnd $10 \mathrm{mg}$ daily, quick relief of symptoms occurred. Within 10 days ferritin $(127 \mu \mathrm{g} /)$ and CRP (5 mg/l) regressed. Given the short time of relapse, immunosuppressive therapy with cyclosporin was initiated $(4 \mathrm{mg} / \mathrm{kg}$ body weight). Since that time the patient remained symptom free for over 8 months.

\section{Discussion}

Serum ferritin is an acute-phase reactant and usually used as a marker of iron storage. Reference range of ferritin differ from laboratory to laboratory as in our case report (e.g. City Hospital with normal range 23-110 $\mu \mathrm{g} / \mathrm{l}$;
University Hospital with normal range 13-150 $\mu \mathrm{g} /)$. In the literature other normal values (40-200 $\mu \mathrm{g} / \mathrm{l})$ have been indicated [3]. These differences might be caused by the properties of the different methods of analysis or device-specific conditions. Most published studies focused on the potential usefulness of serum ferritin assay for diagnosing AOSD. The main goal was to identify a threshold above which ferritin elevation suggested AOSD. In most studies, this threshold was five times the normal value, i.e. $1000 \mu \mathrm{g} / \mathrm{l}$ [4].

Elevated levels of serum ferritin can be detected in various diseases such as infections, malignancies, liver diseases like haemochromatosis or Gaucher's disease, and in the haemophagocytic syndrome $[3,4]$. Except in the haemophagocytic syndrome serum ferritin levels in AOSD are usually much higher than in any other autoimmune or inflammatory diseases. Levels between 3,000 and $30,000 \mu \mathrm{g} / \mathrm{l}$ are not uncommon [3]. Thus, a serum ferritin level of $>1000 \mu \mathrm{g} / \mathrm{l}$ should clinician think of AOSD [4]. In a retrospective French study a threshold of $1,000 \mu \mathrm{g} / \mathrm{l}$ of serum ferritin has been used as diagnostic marker for AOSD. Whereas sensitivity was acceptable with $80 \%$, specificity was low at $41 \%$ [5]. Similar data were found in a Japanese study with a sensitivity of $82 \%$ and a specificity of $46 \%$ [1]. Disease activity correlates relatively well with the serum ferritin level which often normalises during remission [6]. In addition, serum ferritin might serve as a prognostic marker in AOSD [7].

Glycosylated ferritin (GF) has been suggested as another diagnostic tool [6]. Healthy subjects normally show $50 \%-80 \%$ of glycosylated ferritin in the serum. This fraction declines to $20 \%-50 \%$ in patients with inflammatory diseases [4] and down to $20 \%$ in AOSD, which suggests a specific phenomenon in AOSD. Recent studies showed a GF $20 \%$ decline sensitivity of $78 \%$ and specificity of $64 \%$ [5]. The combination of both, hyperferritinaemia and GF $20 \%$, revealed a sensitivity of $67 \%$ and specificity of $84 \%$ [8]. Although the serum ferritin level fluctuates during systemic inflammation, GF remains low several weeks to months after disease remission [8]. However, a low level of GF is not specific to AOSD; it is observed also in other inflammatory processes like in severe systemic infections [5] or haemophagocytic syndromes [9].

Classification criteria of AOSD are based on retrospective studies. In a comparative study [10] it has been found that Yamaguchi's criteria [1] were the most sensitive (93.5\%) followed by Cush's [11] (80.6\%) and Calare's [12] $(80.6 \%)$. Due to lack of control groups, specificity could not be evaluated [10]. In 2002, using GF new classification standards for AOSD have been proposed. Based on these criteria sensitivity for AOSD was $80.6 \%$ with a specificity of $98.5 \%$ [13]. 
In conclusion, diagnosis of AOSD is uncommon. Particularly in times of global pandemic flu and fast living life style when patients rush from one doctor to another clinic and vice versa the diagnosis of AOSD is even more difficult. Based on our report and the latest literature data, we advocate in suspicion of a probable AOSD to measure serum ferritin. Determination of GF in the daily clinical practice is not feasible and is provided only by specialized laboratories. In addition, serum ferritin might serve as disease activity marker.

\section{REFERENCES}

[1] M. Yamaguchi, A. Ohta, T. Tsunematsu, R. Kasukawa, Y. Mizushima, H. Kashiwagi,S. Kashiwazaki, K. Tanimoto,Y. Matsumoto, T. Ota, et al., "Preliminary Criteria for Classification of Adult Still's Disease," Journal of Rheumatology, Vol. 19, No. 3, March 1992, pp. 424-430.

[2] B. Fautrel, "Adult-Onset Still Disease," Best Practice \& Research Clinical Rheumatology, Vol. 22, No. 5, 2008, pp. 773-792.

[3] V. Bagnari, M. Colina, G. Ciancio, M. Govoni and F. Trotta, "Adult-Onset Still's Disease," Rheumatol International, Vol. 30, No. 7, 2009, pp. 855-862.

[4] B. Fautrel, "Ferritin Levels in Adult Still's Disease: Any Sugar?” Joint Bone Spine, Vol. 69, No. 4, 2002, pp. 355-357.

[5] B. Fautrel, G. Le Moël, B. Saint-Marcoux, P. Taupin, S. Vignes, S. Rozenberg, et al., "Diagnostic Value of Ferritin and Glycosylated Ferritin in Adult Onset Still's Disease," Journal of Rheumatology, Vol. 28, No.2, 2001, pp. 322-329.

[6] C. Van Reeth, G. Le Moël, Y. Lasne, M. C. Revenant, J.
Agneray, M. F. Kahn, et al., "Serum Ferritin and Isoferritins are Tools for Diagnosis of Active Adult Still's Disease," Journal of Rheumatology, Vol. 21, No.5, 1994, pp. 890-895.

[7] T. Zeng, Y. Q. Zou, M. F. Wu and C. D. Yang, "Clinical Features and Prognosis of Adult-Onset Still's Disease: 61 Cases from China," Journal of Rheumatology, Vol. 36, No. 5, 2009, pp. 1026-1031.

[8] S. Vignes, G. Le. Moël, B. Fautrel, B. Wechsler, P. Godeau and J. C. Piette, "Percentage of Glycosylated Serum Ferritin Remains Low throughout the Course of Adult Onset Still's Disease," Annals of the Rheumatic Diseases, Vol. 59, No.5, 2000, pp. 347-350.

[9] L. Fardet, P. Coppo, A. Kettaneh, M. Dehoux, J. Cabane and O. Lambotte, "Low Glycosylated Ferritin, a Good Marker for the Diagnosis of Hemophagocytic Syndrome," Arthritis \& Rheumatism, Vol. 58, No.5, 2008, pp. 1521-1527.

[10] C. Masson, X. Le Loet, F. Liote, J. J. Dubost, M. C. Boissier, L. Perroux-Goumy, et al., "Comparative Study of 6 Types of Criteria in Adult Still's Disease," Journal of Rheumatology, Vol. 23, No. 3, 1996, pp. 495-497.

[11] J. J. Cush, T. A. Jr. Medsger, W. C. Christy, D. C. Herbert and L. A. Cooperstein, "Adult Onset Still's Disease. Clinical Course and Outcome," Arthritis \& Rheumatism, Vol. 30, No. 2, 1987, pp. 186-194.

[12] J. J. Calabro and A. V. Jr. Londino, "Adult Onset Still's Disease," Journal of Rheumatology, Vol. 13, 1986, pp. 827-828.

[13] B. Fautrel, E. Zing, J. L. Golmard, G. Le Moel, A. Bissery, C. Rioux, et al., "Proposal for a New Set of Classification Criteria for Adult-Onset Still Disease," Medicine, Vol. 81, No. 3, 2002, pp. 194-200. 